\title{
ERRATUM
}

\section{Erratum to: Cost Implications of ACGME's 2011 Changes to Resident Duty Hours and the Training Environment}

\author{
Teryl K. Nuckols, MD, MSHS ${ }^{1,2}$ and José J. Escarce, MD, $P h D^{1,2}$
}

'Division of General Internal Medicine and Health Services Research, David Geffen School of Medicine at the University of California, Los Angeles, CA, USA; ${ }^{2}$ The RAND Corporation, Santa Monica, CA, USA.

$\mathrm{J}$ Gen Intern Med 27(2):262-3

DOI: $10.1007 / \mathrm{s} 11606-011-1827-1$

(c) Society of General Internal Medicine 2011

he original publication omits a correction intended for
Figure $2 \mathrm{~B}$. The complete corrected Figure 2 is reproduced here.

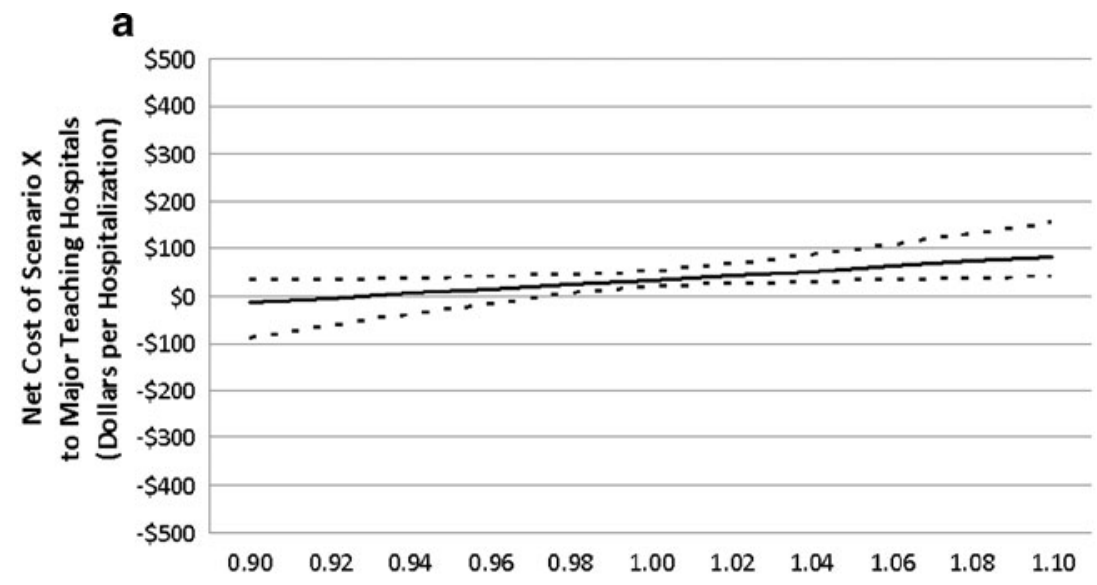

Hypothetical Effect on PAEs (Relative Risk, 2011 vs. 2003 ACGME Policy)

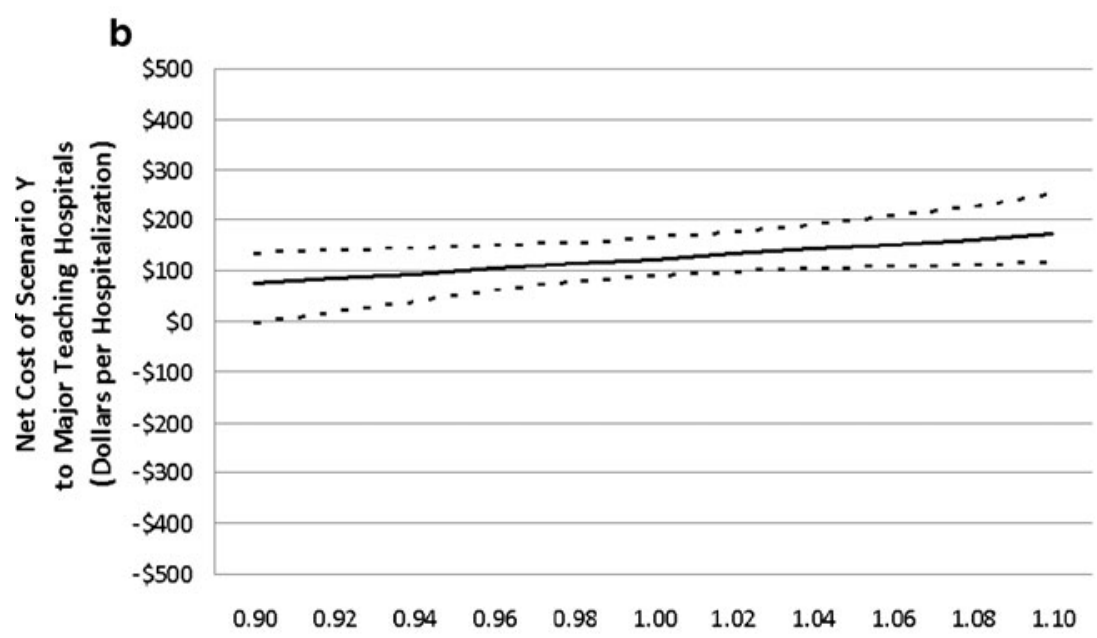

Hypothetical Effect on PAEs (Relative Risk, 2011 vs. 2003 ACGME Policy)

Figure 2. Net cost to major teaching hospitals of ACGME's 2011 Common Program Requirements as a function of the policy's hypothetical effect on preventable adverse events (PAEs). (a) scenario X: most programs reorganize schedules to comply with 16-hour shift requirement; small programs transfer PGY 1s' excess work to other providers. (b) scenario Y: all programs transfer PGY 1s' excess work to other providers. (In this figure, the other providers are a mixture of substitutes). Legend: - mean modeled estimate, ....95\% confidence interval for mean modeled estimate. 
Corresponding Author: Teryl K. Nuckols, MD, MSHS; Division of General Internal Medicine and Health Services Research, David Geffen School of Medicine at the University of California, 911 Broxton Avenue, Los Angeles, CA, 90095, USA (e-mail: tnuckols@mednet.ucla.edu)

The online version of the original article can be found at $h$ ttp://dx.doi. org/10.1007/s11606-011-1775-9.

Published online August 25, 2011 